\title{
Building and Dwelling: Ethics for the City. Richard Sennett. London: Allen Lane, 2018, $342 \mathrm{pp}$.
}

\author{
Dafne Muntanyola-Saura \\ Universitat Autònoma de Barcelona \\ dafne.muntanyola@uab.cat \\ Josep Muntañola-Thornberg \\ Universitat Politècnica de Catalalunya \\ jose.muntanola@upc.edu
}

El tercer volumen de la trilogía sobre la ciudad de Richard Sennett, Building and Dwelling, con el subtítulo Ethics for the City, ha sido publicado tras años de expectación. Construyendo y Habitando, una traducción nuestra, porque todavía no se ha publicado en español, no defraudará a los lectores de los dos volúmenes anteriores, El artesano y Juntos. Se trata de un texto escrito con brillantez narrativa y con argumentos provocadores y que toma partido en los debates actuales entre la ciencia social, la política y la arquitectura sobre el presente y el futuro de la ciudad.

Sennett es un buen escritor y un académico singular, siempre a caballo entre el ensayo y los libros académicos al uso. Sus "naivetées" siguiendo su costumbre de usar palabras francesas, encarna una feroz opinión disfrazada de sofisticación cultural. La totalidad del libro está atravesada por la dicotomía entre los conceptos de "ville" y "citê", siempre en francés en la lengua original. El primero está relacionado con los "urbanites" o los habitantes de la vida urbana, y el segundo con los "urbanistas", que planifican y diseñan. El juego de palabras y la polisemia es el hilo conductor del libro, para bien y para mal. En la introducción vemos que además aparecen tres categorizaciones urbanísticas, el plan "abierto" (open), "modesto" (modest) y "estropeado" o "corrupto"(crooked). El plan abierto es parte del modelo experimental; la modestia curiosamente desaparece del libro y resurge en la conclusión. En cambio, la categoría corrupto, extraída de un texto sobre las ciudades cosmopolitas de Kant, toma protagonismo filosófico a lo largo del libro. Sennett está en contra de la "citê" cerrada, ejemplo para él de clasismo y racismo. Así, la "viIle" debería ayudar a abrir socialmente la "citê", que depende de la ética de la planificación.

La primera parte del libro, Las dos ciudades, describe la fundación un tanto inestable del urbanismo moderno a partir de tres gigantes, Cerdá, Hausmann y OImstead. A Idelfons Cerdá le adjudica ser el padre de una "igualdad social" a través de la trama, a Hausmann de ser el responsable de una nueva movilidad basada en la invención de los porches de venta comercial en la vía pública, y a Olmstead de crear los parques públicos haciendo entrar la ville en la cité. Sennett admite que ninguno presenta un proyecto de ciudad completo sino aspectos inmersos en un mar de contradicciones entre urbanitas y urbanistas. Su valiosa crítica podría haber ido más allá, y sus ejemplos, como también sucede en su anterior volumen Juntos ( Together, véase reseña de Muntanyola-Saura, 2012) surgen de un conocimiento histórico a menudo insuficiente. Ni Haussman se inventa los porches, ni Cerdá es el padre de una igualdad social. La idea de repartir los espacios verdes por la ciudad desapareció enseguida en el primer plano oficial de Cerdá, en el que los bloques del Eixample se comían no solo el interior de manzana, que pasaba a ser de uso y propiedad privada, sino también los parques ya existentes en Barcelona que se cubrían con bloques de viviendas hasta el infinito. Se han encontrado certificados históricos originales firmados por Cerdá clamando las virtudes del uso privado de los terrenos dentro y fuera de las manzanas, por creer 
que sería un despilfarro para el Estado mantener la propiedad pública (Saura,1984). Cerdá no fue una excepción de su tiempo: era un reformista que seguía la tradición de Reynaud, Le Play y Quêtelet en Francia. Así, su censo de familias de Ciutat Vella, el primero en Europa, tiene un gran valor sociológico como ejemplo de la estadística correctiva que manejaban los economistas sociales del momento, preocupados por el orden social y que buscaban conocer la realidad social para evitar el cambio revolucionario.

Sennett sintetiza tres aportaciones sociólogicas que explican en parte el divorcio entre la citéy la ville: Simmel y la actitud de indiferencia del ciudadano blasé, que renuncia a ver lo que le molesta; Whyte y sus estudios etnográficos sobre cómo la gente ocupa el lugar urbano buscando un contacto y una cercanía espacial, aunque sea superficial; y Weber, que recoge el dicho medieval El aire de la ciudad nos hace libres y que pone de manifiesto la contingencia histórica de una visión optimista de lo que significa ser ciudadano. Luego, el autor analiza la progresiva separación de la villey la cité. Nos encontramos aquí con el mejor Sennett, por su capacidad de sintetizar en pocas frases la falta de una articulación entre la ville y la cité, los errores de la Carta de Atenas, hasta llegar al debate fulminante entre Jane Jocobs y Lewis Mumford. Recoge las dos propuestas de estos autores clásicos del siglo xx, la de Jacobs que aboga por lo local y espontáneo, y la de Mumford que reclama una ciudad jardín holística y políticamente comprometida con los más desfavorecidos.

Sennett se olvida de historiadores y sociólogos de la arquitectura como Bauer (esposa de Wurster de la escuela de Warburg), académica de la costa oeste que reivindicó a Mumford ante la indiferencia de su contraparte neoyorquina, tradicionalmente más conservadora que la californiana. En una visita personal a Mumford en 1963 del segundo firmante de esta reseña, un entonces joven estudiante se encontró ante un Mumford ya mayor, amable y frustrado con la actitud despectiva de los neoyorquinos que le consideraban un conservador, cuando él, por el contrario, era un gran conocedor y amante de las vanguardias revolucionarias, admirador de Frank Llloyd Wright, Neutra y Shindler (Muntañola, 2017), pero crítico con la modernidad inhumana de Le Corbusier y de los defensores del International Style. Acaba Sennett el capítulo diciendo que Mumford tenía gran parte de razón en sus propuestas críticas. Además, cuenta como Jacobs en su última conversación le despidió con un elocuente ¿Y tú qué harías?, animándole a desarrollar su propia visión como urbanista en acción.

La segunda parte, La dificultad de habitar, empieza contraponiendo una ville como Delhi, que crece en la informalidad con urbanitas sin urbanistas, con Shangai, cité donde un urbanismo desde arriba choca con los urbanitas. El lector se cruza el Ángelus objeto de admiración de Benjamin, símbolo de la narrativa de la totalidad, con un Heidegger nazi que se recluye en una cabaña en el bosque huyendo de las ciudades socialmente contaminadas por el cosmopolitismo (y rodeado de estudiantes y colegas antisemitas) y con un Levinas que ofrece una visión ontológica del vecino como enemigo, desde un infinito social. Sennett delimita así las tres negaciones de la ciudad democrática: la huida, el aislacionismo y la homogeneización. Las comunidades cerradas de los que huyen de la ciudad por no soportar las diferencias sociales, los campos de refugiados que son privados de libertad y los lugares de trabajo que construyen ficciones sin vida social real son ghettos que aparecen de manera sorpresiva. Con ello plantea el problema urbano sin perdonar a nada ni a nadie.

El símbolo del Angelus pone de manifiesto la angustia vital de la vida humana que se mueve entre la raíz del lugar y el movimiento hacia adelante, el eterno cambio que nos lleva al futuro. Sennett busca así la complejidad propia de un Renacimiento 0 de un Barroco, y huye de la simplificación que de forma muy perspicaz delimita como el modelo urbanístico comercial y estandarizado de Starbucks y las grandes cadenas de los centros de las ciudades. Así, la gentrificación no sería simplemente un problema de colonización de grupos de artistas y hipsters. Sennett explica como actualmente la gentrificación encarna la separación espacial de clase, un lugar habitado por miembros de una clase social homogénea. Se trata fundamentalmente de un proceso por el cual el $75 \%$ de la población esta sometida a perder su vivienda y ser expulsada de la ciudad por el $25 \%$ restante que controla el mercado de los alquileres y el uso del espacio. 
El capítulo que cierra esta parte es otro de nuestros favoritos, y aborda la figura de Tocqueville vinculándolo con una original crítica a lo digital. Sennett parte del concepto central de francés, el individualismo, que recoge la familiaridad como valor para atacar a lo público. La familiaridad es consecuencia de una igualdad de condiciones, que no una igualdad de oportunidades. Se trata de una forma de consumo y de estandarización del gusto. A partir de aquí, Sennett reivindica la necesidad de comprender, y no solo de utilizar, los procesos y objetivos que están detrás de la tecnología y de lo digital. Su ignorancia nos lleva a un proceso de estupidización y de submisión a unos pocos expertos programadores que toman decisiones por nosotros en la esfera del big data comercial y científico. Para luchar contra la forma simplificada de utilizar el móvil y el ordenador, Sennett plantea la posibilidad de crear smart cities que respeten en ciudadano que piensa, mediante la atención focalizada y la complejidad, con contrafactuales y procesos abductivos, en lugar de caer en estereotipos y explicaciones superficiales.

La tercera parte, Abriendo la ciudad, retoma el desafío de Jacobs sin el entusiasmo intelectual de las primeras partes del libro. Presenta ejemplos de cómo la cité, la ville y sus relaciones pueden mejorar y fomentar la cooperación en todas sus formas, en línea con Juntos. Incluye casos de estudio en Medellín, Washington DC, Nueva York, Amsterdam y Chile. Es interesante la idea de buscar lo fronterizo, las transiciones liminales entre barrios y usos para construir una urbe membrana, porosa y compleja. Las intervenciones citadas tienen en común la voluntad de crear formas de comunicación y de transporte eficientes entre zonas con estatus socioeconómico distintos. Sin embargo, la diversidad de ejemplos y de teorías no acaban de convencer a los lectores, que pierden el hilo argumental y no acaban de comprender cuáles son las alternativas viables en sentido urbanístico y por qué unas funcionan mejor que otras. Además, las intervenciones no dejan de ser muy parciales, algunas puramente estéticas, como las de mobiliario urbano, que aun siendo interesantes no constituyen alternativas serias a la ciudad pulpo con la que las Naciones Unidas etiqueta los conglomerados urbanos actuales.
El capítulo siguiente, con el inteligente título del Competente urbanita recoge de nuevo las razones del fracaso urbanístico: el crecimiento exponencial del capitalismo salvaje y financiero (la gentrificación), el aislamiento (ghetto) y la estúpida frivolidad (el suburbio). El impacto social de estos procesos es enorme, ya que para Sennet el lugar tiene un rol crucial para explicar la vida social de la modernidad: Where is the first thing to assess to understand what in modern times (p. 179). A su vez, las competencias sociales de la gente urbanita, autónoma, libre y feliz en la ciudad contemporánea, incluyen ante todo la curiosidad, la imaginación y la capacidad de pensar de manera dialógica. Concretamente, Sennett alaba las virtudes del paseante que ve más que el conductor, en un elogio de la lentitud que encaja con las criticas ya habituales sobre la velocidad de la posmodernidad. La mirada atenta y corpórea (embodied en términos de Sennett) es la que nos enraiza en lo urbano, transformando un espacio abstracto e inhumano en un lugar habitado y vivido: Lateral accounting is one of the criteria for distinguishing place- a site on which you dwell- from space- a site you move through (p. 185).

En los capítulos siguientes, se dan ejemplos de socialidad que se basan en el consumo (beber, comer o comprar con otr@s) pero que no incluyen la esfera del trabajo. Parece ser que la ciudad contemporánea está condenada a ser un lugar de consumo y no de producción, obligando a sus habitantes a largas horas de commuting que son, y numerosos estudios lo demuestran, grandes fuentes de alienación y de estrés. Sennett da una definición de socialidad muy restrictiva, que recuerda la indiferencia de Goffman (1967): Sociality names feeling a kind of limited fraternity with others based on sharing an impersonal task (p. 260). Pero Simmel (1908), aunque Sennett parece ignorarlo al afirmar que el autor no ofrece una definición de socialidad, parte de una perspectiva mucho más amplia y completa: Sociality is a fleeting process open to the unexpected. Se trata de una aproximación formalista que separa el espacio puro del lugar, que surge del encuentro, la asamblea y la simultaneidad. La respuesta de Sennett a Jacobs es una planificación urbanística concreta, corpórea, enactiva, contrafactual e imaginativa. Sin embargo, todo ello son atributos mi- 
crosociológicos. A escala macro, la ciudad abierta propuesta por Sennett rehuye el ideal de buena vida de Mumford, políticamente responsable. Sennett pone en cuestión que los urbanitas quieran una trayectoria vital estable y parece considerar no ya inevitables, sino deseables, trayectorias migrantes precarias vinculadas a las dinámicas de inversión del capital inmobiliario a nivel global. En lugar de dar por sentada esta fragmentación y provisionalidad, ¿por qué no hacemos visibles los procesos de decisión económicos y políticos que están detrás de la desigualdad de clase en términos de renta, propiedad y licencias comerciales de uso del suelo? La propuesta de David Harvey (2017) en su último libro pone de manifiesto la lógica estructural del antivalor, que somete toda actividad social a un mercado inmobiliario autónomo y que conlleva, necesariamente, la devaluación de sectores económicos productivos, como la industria 0 el comercio.

Todo ello se ve mas claro en la cuarta parte Ética para la ciudad y en las conclusiones en las que Sennett dibuja y explica el progresivo deterioro de la tolerancia social en la convivencia espacial urbana. El autor insiste en la imagen de la ciudad estropeada y corrupta de Kant como raíz de la exclusión, que vincula al antisemitismo de Heidegger, con ramificaciones en la herencia cristiana. Se trata de un terreno psicosocial, el paso gradual entre lo físico y lo mental, que es muy resbaladizo. Y es que, en un profético y casi dramático final, Sennett describe sus paseos por la Kantstrasse de Berlín, en plena rehabilitación después de sufrir una embolia. Ante su patente dificultad para mantener el equilibrio, la gente le mira y pasa de largo sin preguntarle nada ni mostrar interés alguno. En cierta manera, Sennett no deja de sorprenderse y de intentarnos sorprender por lo que sucede en sus paseos urbanos, como si tamaña indiferencia social fuese algo imprevisible. Pero muchas de esta sorpresas ya están estudiadas y obedecen a lógicas económicas y políticas de carácter estructural, ya denunciadas precisamente por Lewis Mumford, que en la obra de Sennett no dejan de ser un fantasma en el background.

$Y$ aunque "casual" que sucediera en la Kantstrasse, la anécdota deja en suspenso si la ética psicosocial que sirve de hilo conductor del libro efectivamente existe, si alguna vez ha existido, 0 si por el camino ha desaparecido. Quizá Kant tenía razón al hablar de la naturaleza corrupta de la ciudad cosmopolita moderna y de su mezcla cultural sin dialogía social, habitada por una sociedad líquida 0 indiferente a la diferencia. Durante los ultimos años de su vida, Kant trató de encontrar la parte de razón que le faltaba. Aristóteles la encontró en sus libros que sintetizan la sabiduría espacial y arquitectónica de la persona que articula ética y política. Podría ser el siguiente libro de Richard Sennett, que seguiremos esperando. En el límite entre la selva y el paraíso, donde el espacio humano sigue existiendo, quizá nos quede todavía mucho más por descubrir del futuro de lo social.

\section{REFERENCIAS AÑADIDAS}

Bauer, C. (1965). The social front of the modern architecture. Journal of The Society of The Architecture Historians, 24.

Goffman, E. (1967). Interaction ritual. New York: Doubleday.

Harvey, D. (2017). Marx, Capital and the Madness of Economic Reason. London: Profile Books.

Muntañola, J. (2017). Arquitectura y Modernidad. ¿Suicidio o Reactivación? Arquitectònics, 29 Edicions UPC.

Muntanyola-Saura, D. (2014). Book review of Together (Sennett, 2012). PAPERS Revista de Sociología, 99: 3.

Saura, M. (1984). Informe de las Metodologías del Taller de Rehabilitación de l' Eixample. ETSAB, Universitat Politècnica de Catalunya.

Simmel, G. (1908). Sociología. Madrid: Ariel. 